PHYSICAL ASPECTS OF COLOUR 


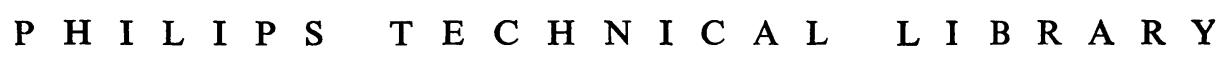

\section{PHYSICAL ASPECTS OF COLOUR}

AN INTRODUCTION TO THE SCIENTIFIC STUDY OF COLOUR STIMULI AND COLOUR SENSATIONS

Dr. P. J. BOUMA

Second edition

edited by

W. de GROOT

A. A. KRUITHOF

J. L. OUWELTJES

Macmillan Education 
ISBN 978-1-349-00960-2 ISBN 978-1-349-00958-9 (eBook)

DOI 10.1007/978-1-349-00958-9

(C) N.V. Philips' Gloeilampenfabrieken, Eindhoven (The Netherlands), 1971

Softcover reprint of the hardcover 2nd edition 1971 978-0-333-11527-5

All rights reserved. No part of this publication may be reproduced or transmitted, in any form or by any means, without permission.

\author{
Published by \\ MACMILLAN AND CO LTD \\ London and Basingstoke
}

Associated companies in New York, Toronto, Melbourne, Dublin, Johannesburg and Madras

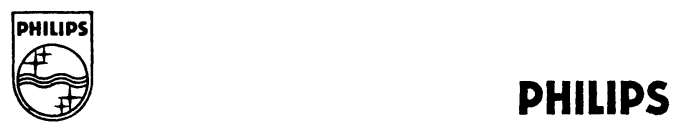

Trademarks of N.V. Philips' Gloeilampenfabrieken

No representation or warranty is given that the matter treated in this book is free from patent rights: nothing herein should be interpreted as granting, by implication or otherwise, a licence under any patent rights 


\section{PREFACE TO THE SECOND ENGLISH EDITION}

The original Dutch text of Bouma's book, written between September 1944 and September 1945, was published in November 1946, a few months before the death of the author on January 19, 1947.

An English edition, published under supervision of the first undersigned, was achieved in November 1947. A few additions to the original were made, most of them derived from posthumous papers of the author, published in 1946 and 1947.

When, in 1965, the present publisher asked us to prepare a second English edition, to be made with the permission of Mrs. C. J. Bouma-Querner, it was clear to us from the outset that the order of treating the main subjects of the original and the wording of the first Dutch edition should be maintained as far as possible. A number of changes was, however, inevitable. First of all the names of quantities and technical terms, the symbols and definitions for quantities and the names and symbols for units had to be brought into accordance with the newest C.I.E. vocabulary (now in preparation) and with the ISO recommendations, based on the SI, the International System of Units (1960).

Secondly, although the fundamentals of colorimetry have little changed, the developments of the past twenty years had to be taken into account. This resulted in an extension of the list of references with basic articles for new conceptions, whilst of the older literature only papers of fundamental interest were retained. We thought these restrictions on the list of references to be justified as nowadays for the literature up to 1954 there is the virtually complete compilation in Richter's "Internationale Bibliographie der Farbenlehre" whereas for the literature of recent years the system issued by "die Farbe" provides all the necessary information. For the same reason in some chapters new sections had to be added and other sections rewritten or extended.

In the third place it seemed desirable to shift certain subjects from one chapter to another. Thus, for instance, the information on the colour atlases of Ostwald and Munsell, originally to be found in the chapter on the historical development (Ch. XI), has been shifted to $\mathrm{Ch}$. IX.

As was the case with the first translation, the text has been revised as to technical expressions and idiom, especially the parts rewritten or added. We are greatly indebted to Mr. H. Carter for the accurate fulfilment of this task.

We hope that also in its new form Bouma's book may prove useful to all those interested in colour science.

W. de Groot

A. A. Kruithof

J. L. Ouweltjes 


\section{TABLE OF CONTENTS}

Chapter I. INTRODUCTION. . . . . . . . . . . . . . . . . . . 1

$\S 1$. Dramatis personae . . . . . . . . . . . . . . . . . 1

$\S 2$. The sun as a source of light . . . . . . . . . . . . . . . 1

§3. Coloured objects. . . . . . . . . . . . . . . . . . . 8

§4. The part played by the eye ............... . 10

$\S 5$. The fundamental number three in the colour problem. . . . . . . . . 13

$\S 6$. Experimental confirmation of the part played by the number three . . . 14

§7. Comparison of the set of colours with other three-dimensional sets . . . 16

§ 8. The physiological significance of the number three . . . . . . . . . . 17

$\S 9$. Brightness as one of the characteristics of colour . . . . . . . . . . . 18

Chapter II. BRIGHTNESS AND LUMINANCE . . . . . . . . . . . . 20

$\S 10 . \quad$ A general survey of the subject . . . . . . . . . . . . . . . . . 20

§11. Brightness. . . . . . . . . . . . . . . . . . . 20

§12. Relative luminous efficiency curves . . . . . . . . . . . . . . . . . 22

§13. Additivity . . . . . . . . . . . . . . . . . . . . . 26

§14. Luminance . . . . . . . . . . . . . . . . . . . . . . . . . . . 28

$\S 15$. Some photometric quantities . . . . . . . . . . . . . . . . . . . 29

§ 16. The Purkinje phenomenon . . . . . . . . . . . . . . . . . . . . 31

Chapter III. THE COLOUR TRIANGLE . . . . . . . . . . . . . . . . . 32

$\S 17$. The possibility of representing colour sensations in a plane diagram . . 32

$\S 18$. Building up the colour triangle .............. 33

$\S 19$. The introduction of "negative amounts" of a matching stimulus, the trichromatic system . . . . . . . . . . . . 36

§ 20. Representation of chromaticities with positive co-ordinates only . . . . 37

\$21. Dominant wavelength, complementary wavelength and colorimetric purity; the monochromatic system . . . . . . . . . . . . . . . . . . 38

§ 22. Additive complementary colours . . . . . . . . . . . . . . . . . . 39

Chapter IV. COLOUR SPACE IN ITS SIMPLEST FORM . . . . . . . . . 41

§ 23. Representation of colours in space, GrassMANN's first law . . . . . . . 41

§24. Grassmann's second law, position of the spectral colours . . . . . . . 42

$\S 25$. Representation of mixtures of colour stimuli in space; GraSSMANN's third law. . . . . . . . . . . . . . . . 44 44

§26. The connection between colour space and the plane chromaticity diagram 47

$\S 27$. Conclusions from the connection between colour space and the colour plane. . . . . . . . . . . . . . . . . 50

§ 28. Other colour spaces and chromaticity diagrams . . . . . . . . . 52

Chapter V. THE C.I.E. CO-ORDINATE SYSTEMS . . . . . . . . . . . . . 53

$\S 29$. Introduction of the C.I.E. 1931 standard colorimetric system $\ldots \ldots$. . 53

§30. The C.I.E. 1931 chromaticity diagram . . . . . . . . . . . . . . . 57

§31. General transformations of colour space . . . . . . . . . . . . . . 61

§32. General transformations of the colour plane . . . . . . . . . . . . . 63

§33. Amount of a colour; trichromatic unit . . . . . . . . . . . . . . . 64

§34. Requirements a transformation can fulfil . . . . . . . . . . . . 65 
§ 35. Applicability of the C.I.E. 1931 system; the C.I.E. 1964 supplementary system . . . . . . . . . . . . . . . . . . . . . . . . . . . .

§36. Relations between the C.I.E. 1931 system and the monochromatic system

Chapter VI. LIGHT SOURCES AND THEIR COLOUR CO-ORDINATES IN THE C.I.E. 1931 SYSTEM . . . . . . . . . . . . . 71

§37. Calculation of the colour co-ordinates of a light source . . . . . . . . 71

§38. Examples of light sources having a line spectrum . . . . . . . . 74

$\S 39$. Thermal radiation; the full radiator . . . . . . . . . . . . 77

$\S 40$. Calculation of the colour point of a full radiator; results . . . . . . 79

$\S 41$. Thermal radiators; colour points; distribution temperature; colour temperature . . . . . . . . . . . . 85

$\S 42$. The meaning of the word "white"; C.I.E. standard illuminants. . . . . 87

§43. Blended light sources . . . . . . . . . . . . . . . . . . . 92

$\S 44$. Metameric lights . . . . . . . . . . . . . . . . . 94

\section{Chapter VII. COLOUR CO-ORDINATES OF OBJECT COLOURS IN THE} C.I.E. SYSTEM . . . . . . . . . . . . . . . . . . . 96

§45. Calculation of the colour coordinates of an object colour . . . . . . 96

$\S 46$. Examples of object colours . . . . . . . . . . . . . . . . . 100

$\S 47 . \quad$ Metameric object colours . . . . . . . . . . . . . . . . . . . . . 106

$\S 48$. Boundary colours . . . . . . . . . . . . . . . . . . . . . . . . 109

$\S 49$. Combinations of boundary colours . . . . . . . . . . . . . . 113

$\S 50 . \quad$ Ideal and optimal colours . . . . . . . . . . . . . . . . . 117

$\S 51$. Applications of the theory of ideal and optimal colours . . . . . . . 120

§52. Full colours . . . . . . . . . . . . . . . . . . . 122

Chapter VIII. COLORIMETRY. . . . . . . . . . . . . . . . . . . . . 126

§53. Physical and visual colour measurement. . . . . . . . . . . . . . . 126

§54. Spectrophotometry . . . . . . . . . . . . . . . . . . . 127

§ 55. Physical colorimetry with the three-filter photoelectric colorimeter . . . . 132

§56. Visual trichromatic colorimeters . . . . . . . . . . . . . . . . 134

§ 57. Calculation of the C.I.E. 1931 standard tristimulus values from the data provided by the visual trichromatic colorimeter . . . . . . . . 139

§58. Other visual colorimeters . . . . . . . . . . . . . . . . . . 140

Chapter IX. VISUAL INSPECTION OF COLOUR SAMPLES . . . . . . . . 144

$\S 59$. Colour determination with the aid of coloured samples . . . . . . . . 144

$\S 60$. Colour specification with the aid of a colour atlas . . . . . . . . . 146

$\S 61$. Colour systems based on additive mixing of colour stimuli . . . . . 147

$\S 62$. Colour systems based on colour sensations . . . . . . . . . . . . 151

$\S 63$. Colour systems based on specific reproduction techniques . . . . . . 154

Chapter X. DEFECTIVE COLOUR VISION . . . . . . . . . . . . . . . . 157

$\S 64$. The normal and the abnormal eye. Survey of defective colour vision . . 157

$\S 65$. Anomalous trichromats . . . . . . . . . . . . . . . . . . . 159

$\S 66$. Dichromats . . . . . . . . . . . . . . . . . . . . . . . 161

§67. Dichromats (continued) . . . . . . . . . . . . . . . 163

§68. Monochromats or achromats; total colour blindness . . . . . . . . 166

$\S 69$. Physiological background of defective colour vision . . . . . . . . . 167 
$\S 70 . \quad$ Heredity of the defects . . . . . . . . . . . . . . . . 168

Chapter XI. THE HISTORICAL DEVELOPMENT OF COLOUR SCIENCE • 172

§71. Introduction, the pre-Newtonean era . . . . . . . . . . 172

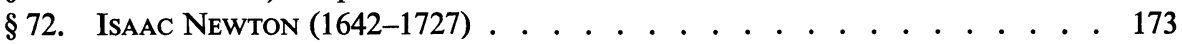

§73. JOHANN WOLFGANG VON GoETHE (1749-1832) . . . . . . . . . . . 175

§74. Young, Grassmann, Maxwell etc. . . . . . . . . . . . . . . . . 178

§75. HelmHoltz, KöNIG and their school . . . . . . . . . . . . . . . . 179

§76. Other theories of colour vision . . . . . . . . . . . . . . . . . . 180

§ 77. Wil helm OstWALd $(1853-1932) \ldots \ldots \ldots \ldots$

§ 78. The further development of the experimental side of colorimetry . . . . 183

§79. Conclusions from the historical facts. Further outlook . . . . . . . . 184

Chapter XII. COLOUR DIFFERENCES． . . . . . . . . . . . . . . . . . 186

$\S 80$. The observation of colour differences . . . . . . . . . . . . . . 186

§81. Experiments on colour discrimination. . . . . . . . . . . . . . . . 188

§ 82. Condensed representation of limens; UCS mixture diagrams . . . . . 196

$\S 83$. Most resembling colour; comparison of colour differences . . . . . . 206

\$84. Uniform colour space . . . . . . . . . . . . . . . . . . . . . . 208

Chapter XIII. THE CHARACTER OF COLOUR SENSATIONS . . . . . . 210

§85. Colour sensations in everyday life . . . . . . . . . . 210

§ 86. Chromatic adaptation; general considerations . . . . . . . . . . . 210

§ 87. Chromatic adaptation; mathematical formulation . . . . . . . . . . 212

\$88. Chromatic adaptation; experimental investigation . . . . . . . . 213

§89. Chromatic adaptation; practical consequences . . . . . . . . . . 214

\$90. Memory colours . . . . . . . . . . . . . . . . . . 215

$\S 91$. Contrast phenomena . . . . . . . . . . . . . . . . . . . . . 215

§92. The BezoLD-BRÜCKE phenomenon . . . . . . . . . . . . . . . . . 217

§93. Conclusion . . . . . . . . . . . . . . . . . . . . . . . . . 218

Chapter XIV. PRACTICAL APPLICATIONS . . . . . . . . . . . . . . . 219

\$94. Introduction. . . . . . . . . . . . . . . . . . . . . . . . . 219

§95. Illuminating engineering. Colour rendering of light sources . . . . . . 219

§96. Specification of the colour rendering properties . . . . . . . . . 221

§97. Artificial daylight . . . . . . . . . . . . . . . . . . 225

§98. Signal lights . . . . . . . . . . . . . . . . . . . . . 227

§99. Colour reproduction, general remarks _. . . . . . . . . . . . 229

$\S 100$. Colour television . . . . . . . . . . . . . . . . . . . . . . . . 229

$\S 101$. Colour television; choice of the primaries . . . . . . . . . . . . . . 230

$\S 102$. Colour television; spectral response of the cameras . . . . . . . . . . 232

$\S 103$. Subtractive colour reproduction . . . . . . . . . . . . . . . 233

§ 104. Colour photography . . . . . . . . . . . . . . . . . . . . . 235

$\S 105$. Colour reproduction by printing . . . . . . . . . . . . . . . . . 236

$\S 106$. Colorant formulation . . . . . . . . . . . . . . . . . . . 238

APPENDIX

I Tables for the calculation of colours (A-O) . . . . . . . . . . 240

II List of symbols . . . . . . . . . . . . . . . . . 251

III Literature on colour vision . . . . . . . . . . . . . . . . . 254

IV Subject index ..................... 265 